\title{
Pembuatan Kompos Organik dari Kotoran Sapi
}

\author{
Kresna Oktafianto $^{1 *}$; Abdul Ro'uf ${ }^{2}$; Faiz Nur Afnan³ ${ }^{3}$ Rivaldi Avan Yudi² Eva Afrida Lucyana $^{4}$; \\ Kistri Wahyuni ${ }^{3}$; Fidyatul Khasana ${ }^{75}$ \\ ${ }^{1}$ Prodi Matematika; ${ }^{2}$ Prodi Teknik Industri; ${ }^{3}$ Prodi Pendidikan Bahasa dan Sastra Indonesia; ${ }^{4}$ Prodi Pendidikan Matematika; \\ ${ }^{5}$ Prodi Pendidikan Bahasa Inggris Universitas PGRI Ronggolawe Tuban, Indonesia \\ 1*kresnaoktafianto@unirow.ac.id
}

\begin{abstract}
Abstrak
Kurangnya pemahaman masyarakat mengenai manfaat pupuk organik yang berasal dari kotoran sapi menyebabkan sebagian besar warga masyarakat atau petani memanfaatkan limbah kotoran sapi dengan cara pembakaran dan menggunakan limbah kotoran sapi sebagai pupuk ke lahan pertanian tanpa melakukan pengolahan terlebih dahulu. Kotoran sapi yang langsung dicampurkan ke lahan pertanian mengakibatkan tumbuh dan berkembangnya penyakit pada tanaman pertanian yang biasa dikenal dengan "akar brendol". Berdasarkan permasalahan tersebut tim pelaksana melakukan penyuluhan dan pelatihan tentang cara pengolahan limbah kotoran sapi sebagai pupuk kompos organik dengan menggunakan bahan utama EM4, semanggi, dan ditambah bahan lain yang bisa didapatkan oleh warga masyarakat atau petani. Kegiatan pengabdian ini dilakukan kurang lebih 14 jam dimulai dari tahap sosialisasi, memastikan ketersediaan bahan utama dan media pembuatan pupuk hingga praktek langsung bersama warga. Hasil dari kegiatan penyuluhan dan pelatihan pembuatan kompos organik dari kotoran sapi warga mulai paham mengenai manfaat pupuk organik dan tertarik untuk memulai memanfaatkan fermentasi kotoran sapi sebagai media penyubur tanah karena lebih hemat biaya.
\end{abstract}

Kata Kunci: Pupuk Organik, Kotoran Sapi, EM4, Semanggi, Fermentasi

\section{Abstract}

Fewer understand the community about organic fertilizer which is preferable from cow dung is greater than the community utilizing dung farmers by burning and using cow dung for agricultural fertilizer to do processing first. Cow manure directly mixed into agricultural land grows and develops disease in agricultural crops commonly known as "brendol roots". Based on these considerations, the implementation team conducted counseling and training on how to manage cow's waste as organic compost fertilizer using the main ingredients EM4, semanggi fertilizer, and other ingredients that could be obtained by the community or farmers. The dedication activity was carried out in less than 14 hours starting from the socialization activities, the renewal of main materials and the making of media for direct practice with residents. The results of the interesting training and training made organic compost from cow dung began to understand the benefits of organic fertilizer and were interested in starting to utilize cow manure fermentation as a soil fertility media because it was more cost effective.

Keywords: Organic Fertilizer, Cow Manure, EM4, Semnggi Fertilizer, Fermentation

\section{Pendahuluan}

Di era globalisasi ini banyak makanan dan minuman organik yang menjadi perbincangan hangat di dunia. Pada tahun 2010 lalu peningkatan permintaan pasar berbagai produk pertanian organik lokal Indonesia mencapai $60 \%$ dimana penjualan makanan dan minuman organik mencapai US\$ 30.000 .000 (Sentana, 2010). Tidak heran saat ini ketika berkunjung ke supermarket, banyak sekali dijumpai sayur-sayuran dan buah-buahan organik dengan harga yang mahal. Hal tersebut menjadi peluang besar bagi negara Indonesia dan masyarakat pedesaan yang masih konsisten menggeluti bidang pertanian agar lebih inovatif dan berkembang mengikuti kebutuhan pasar dunia, dengan harapan suatu saat Indonesia bisa menjadi kiblat sayur-mayur serta buah-buahan organik.

Pupuk organik adalah pupuk yang sebagian besar berasal dari bahan organik yang terdiri dari tanaman atau kotoran hewan yang telah melalui proses fermentasi, bisa berupa cair atau padat yang digunakan untuk mensuplai objek yang ditentukan (Firmansyah, 2011)(Simanungkalit dkk, 2006). Pembuatan pupuk organik juga telah dilakukan oleh (Putra dkk, 2012) dengan bahan dasar kotoran sapi. Pupuk organik bukan hal yang baru bagi masyarakat yang bekerja sebagai petani, bahkan jauh sebelum revolusi hijau, petani sudah mengaplikasikan pupuk organik untuk tanaman pada tahun 1990-an di Indonesia dengan tujuan 
pelestarian lingkungan dan kesejahteraan masyarakat (Widayanti, 2011)(Rosalia, 2012).

Berdasarkan observasi dan wawancara lansung penulis dengan warga desa Tenggerwetan Kecamatan Kerek didapatkan fakta bahwa rata-rata petani di desa tersebut masih menggunakan pupuk sederhana untuk lahan dan tanaman dalam area pertanian warga, sedangkan tim pelaksana melihat bahwa rata-rata warga atau petani memelihara ternak seperti kambing dan sapi, sehingga tim pelaksana pengabdi bergerak melakukan penyuluhan dan praktek langsung tentang cara membuat pupuk organik yang telah difermentasi dari kotoran sapi kepada para petani di desa tersebut. Pemilihan kotoran sapi selain karena hewan tersebut menjadi salah satu ternak yang banyak dipelihara warga tetapi juga didasarkan pada beberapa penelitian dalam dunia pertanian (Atmojo, 2003). Tim pelaksana berharap kegiatan penyuluhan ini memberikan dampak positif bagi warga sehingga dapat membantu meningkatkan taraf hidup secara ekonomi.

\section{Bahan dan Metode}

Bahan-bahan yang digunakan dalam pembuatan pupuk kompos organik dari kotoran sapi yaitu yang ditunjukkan oleh gambar 1-5.

\section{Bahan yang digunakan:}

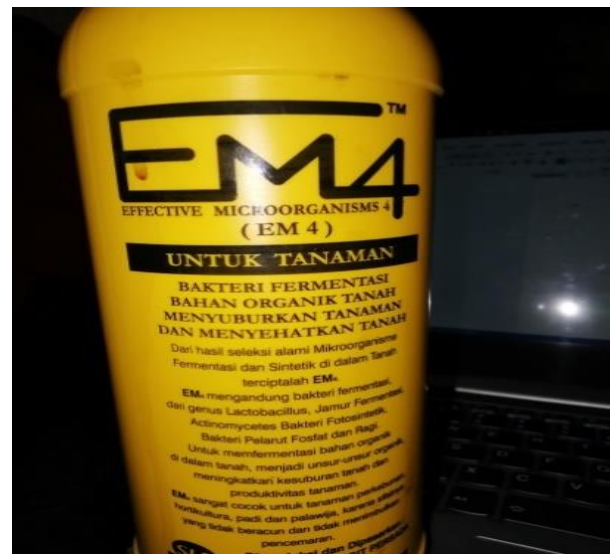

Gambar 1 Larutan EM4

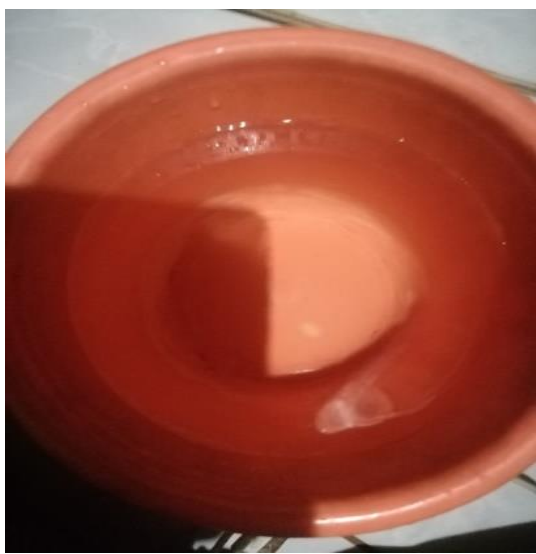

Gambar 2 Air Digunakan Sebagai Campuran EM4 dan Semanggi

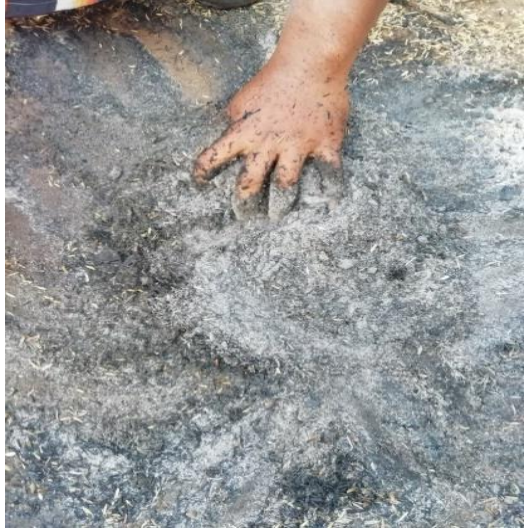

Gambar 3 Dedak Bakar

Dedak bakar digunakan untuk campuran kotoran sapi. Kandungan silika yang terdapat pada dedak bakar akan memperkuat daun sehingga daun-daun akan menjadi lebih tegak dan memperkuat tanaman serta mendorong perkembangan sel-sel tanaman.

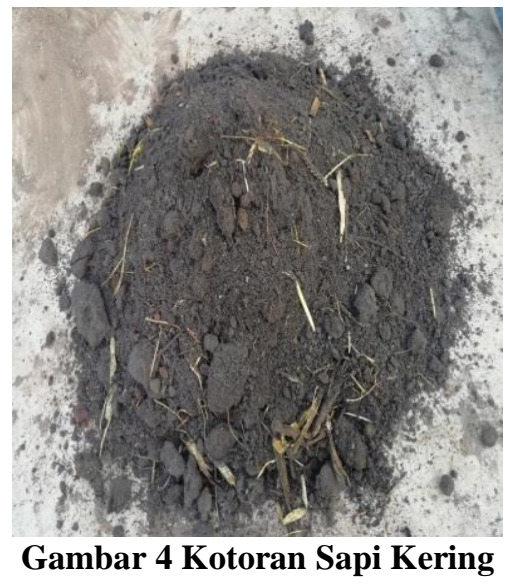

Bahan utama dalam pembuatan pupuk kompos organik yaitu kotoran sapi yang sudah dikeringkan atau dijemur pada sinar matahari.

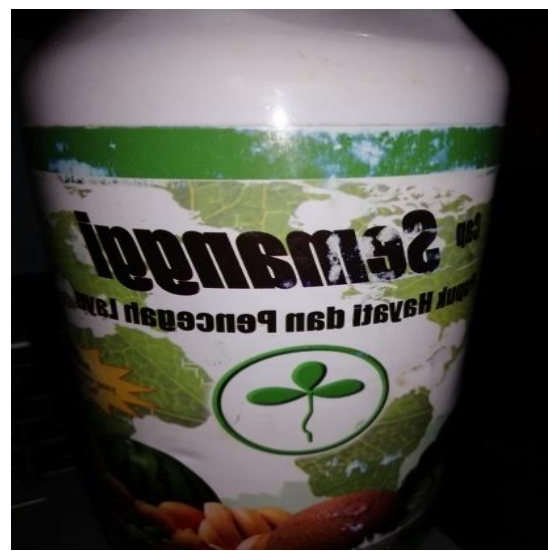

Gambar 5 Pupuk Organik Plus Semanggi

Pupuk organik plus semanggi adalah pupuk organik dalam bentuk granul yang juga mengandung berbagai jenis bakteri yang bermanfaat bagi tanaman. 


\section{Cara Pembuatan :}

1. Menyiapkan bahan berupa kotoran sapi, dedak yang sudah dibakar, EM4, Semanggi, dan air mineral.

2. Kemudian mencampurkan kotoran sapi, dedak dan air yang sudah tercampur dengan EM4 dan Semanggi. Air campuran EM4 dan Semanggi dimasukkan ke dalam alat penyemprot, lalu disemprotkan ke campuran dedak dan kotoran sapi.

3. Setelah itu, campuran kotoran sapi dan dedak disimpan ke dalam plastik, lalu ditutup. Ini bertujuan agar udara tidak bisa masuk.

4. Setelah tiga minggu, plastik dibuka dan dianginanginkan di tempat yang teduh dan dihindari dari paparan sinar matahari. Kompos yang sudah jadi biasanya akan terurai.

5. Kemudian, kompos diayak lalu dikemas. Pupuk kompos siap digunakan.

\section{Hasil dan Pembahasan}

Hasil yang diperoleh dalam program ini adalah warga masyarakat desa Tenggerwetan paham akan pentingnya penggunaan pupuk organik bagi tanaman serta manfaat dalam menjaga mineral tanah agar tetap subur sehingga dalam jangka panjang dapat tetap memberikan hasil panen yang melimpah. Satu hal yang paling penting adalah masyarakat mengetahui cara membuat pupuk organik kimia secara mandiri menggunakan bahan dasar yang ada di sekitar tempat tinggal warga, dalam hal ini kotoran sapi dan kotoran hewan serta EM4. Penyuluhan ini juga membuat warga antusias dan tertarik untuk mulai menggunakan pupuk kandang seperti pupuk kotoran sapi untuk menyuburkan tumbuhan dan tanah pada areal pertanian.

\section{Kesimpulan dan Saran}

Dari hasil penyajian data dan pembahasan sebelumnya maka dapat disimpulkan, bahwa pupuk organik atau bahan organik tanah merupakan sumber nitrogen tanah yang utama dimana peranannya cukup besar terhadap perbaikan sifat kimia dan biologi tanah serta lingkungan. Setelah mengetahui manfaat penggunaan pupuk organik dan cara mengolahnya masyarakan desa Tenggerwetan yang berprofesi sebagai petani diharapkan dapat menghindari penggunaan pestisida sehingga mengurangi resiko keracunan zat tersebut dan mengurangi dampak kerusakan tanah jangka panjang.

Penggunaan pupuk organik buatan sendiri sangat dianjurkan guna menghemat biaya operasional sehingga petani lebih banyak memperoleh laba bersih dari hasil pertanian.

\section{Ucapan Terima Kasih}

Terimakasih disampaikan kepada Universitas PGRI Ronggolawe Tuban terkait pendanaan penuh kegiatan ini mulai dari kegiatan perencanaan hingga pelaporan kegiatan, serta Masyarakat Desa Tenggerwetan Kecamatan Kerek Kabupaten Tuban yang telah berantusias mengikuti kegiatan pembuatan pupuk kompos organik dari kotoran sapi.

\section{Daftar Rujukan}

Atmojo, S. W. (2003). Peranan Bahan Organik Terhadap Kesuburan Tanah dan Upaya Pengelolaannya. Makalah dipresentasikan pada Pidato Pengukuhan Guru Besar Fakultas Pertanian UNS. Surakarta.

Firmansyah, M. A. (2011). Peraturan tentang Pupuk, Klasifikasi Pupuk Alternatif dan Peranan Pupuk Organik dalam Peningkatan Produksi Pertanian. Makalah disampaikan pada Apresiasi Pengembangan Pupuk Organik di Dinas Pertanian. Palangkaraya.

Putra, T.D., dkk. (2012). Paper Pembuatan Kompos dari Kotoran Sapi (Dibuat untuk Memenuhi Tugas Terstruktur Mata Kuliah IPTEK Limbah), diakses dari http://fajarub.blogspot.com/2012/09/ paper-pembuatan-kompos-darikotoran.html. pada September 2019.

Rosalia, A. (2012). Pupuk Kompos, diakses dari http://anggikrosaliaa.blogspot.com/2012/1 0/makalah-pupuk-kompos.html pada September 2019.

Sentana, S. (2010). Pupuk Organik, Peluang dan Kendalanya. Prosiding Seminar Nasional Teknik Kimia "Kejuangan”. Yogyakarta.

Simanungkalit, R. D. M., dkk. (2006). Pupuk Organik dan Pupuk Hayati Organic Fertilizer and Biofertilizer. Litbang, Deptan. Bogor.

Widayanti, S. (2011). Pengertian Komposting, diakses dari http://widayantisuci.blogspot.com/2011/1/ pengertian-komposting.html pada September 2019 